\title{
Evaluation of urban transport management
}

\author{
J. Murphy \& D. O’Cinneide \\ Traffic Research Unit, University College Cork, Ireland
}

\begin{abstract}
The evaluation of a diverse range of transport management measures requires a complex yet pragmatic approach; covering the entire spectrum of impacts on the environment, society, economy, transport and energy. Using a mixed-method evaluation framework, combining qualitative and quantitative data collection methods, provides a broader more comprehensive transport management evaluation. This incorporates environmental and social aspects with the more traditional cost and transport elements. In this paper performance indicators were used in a multi-criteria analysis to monitor the impacts of transport management measures, through the use of ex-ante and ex-post scenarios. A 14-step guide to project evaluation is drawn up. The evaluation requirements for different scales of transport management projects are also considered, as well as the shortcomings of existing techniques. Experience gained from the evaluation of the EU CIVITAS project, MIRACLES, is used to derive future evaluation recommendations.
\end{abstract}

Keywords: EU CIVITAS, MIRACLES, transport management evaluation, performance indicators.

\section{Introduction}

This paper discusses the evaluation of transport management; the evolution of the evaluation framework and the methodology. Evaluation methods recommended are based on a review of the evaluation of transport management measures in Cork as part of the EU project MIRACLES.

In recent years, increased private mobility in metropolitan areas has caused a rapid decrease in the quality of urban environment. Transport related issues such as congestion, poor air quality, noise levels and growing energy consumption are a clear challenge facing European countries. 
Evaluation was an integral part of the EU MIRACLES project from its inception, since evaluation examines how efficiently and effectively a project achieves its objectives. It can also provide interim feedback to provide additional benefit, resulting in improvements to the system. "What is required is a flexible framework that allows timely evaluation evidence to feed into the policy cycle" [1].

\section{MIRACLES project}

As part of the EU CIVITAS (CIty-VITAlity-Sustainability) initiative the MIRACLES project (Multi Initiatives for Rationalised Accessibility and Clean, Liveable Environments) partnered four European cities: Rome (I), Barcelona (E), Winchester (UK) and Cork (IRL). This project aimed to increase the urban transport system's sustainability and efficiency through innovative strategies for clean urban transport. The four strategic goals were to reduce transport related environmental impacts at the local level; to increase urban accessibility; to enhance economic efficiency through better transport management; and to improve citizens' quality of life. Details of the project, which ran from 2002 to 2006, can be found on www.miraclesproject.org.

A diverse and innovative range of 42 measures across the four cities were implemented, varying in scope and scale from restricted access in Rome to the provision of a cycle hire scheme in Winchester.

The MIRACLES measures proposed for Cork were:

Measure 5.1 (Set up of a City Centre Clean Zone). The main thoroughfare in the city centre, was redesigned which reduced the existing four lanes to two, with complimentary traffic management measures including new cycle facilities and additional pedestrian crossings. Retractable bollards were placed on side streets providing access only to residents, emergency services and some delivery services.

Measure 7.3 (Introduction of New Lines) involved the provision of a 900 space park and ride site in the city.

Measure 10.1 (Awareness Measures) involved the introduction of new cycle infrastructure in the city centre consisting of cycle stands and new cycle ways. Measure 10.2 (Mobility Management Measures) consisted of a car-pooling scheme set up by Cork City Council to reduce vehicle trips among its employees and the promotion of sustainable modes of transport.

Measure 11.2 (Improved Network Management) introduced an innovative parking management scheme using mobile phone technology for parking payments and parking information.

Measure 12.2 (Municipal Fleet Vehicles), Cork City Council converted 6\% of its fleet of light vehicles to run on lower emission fuel.

Cork City achieved the following targets [5], through the implementation of the MIRACLES measures:

Reduction of lane capacity by $50 \%$ on the city's main arterial route.

Provision of a new park and ride, and maintain at over half capacity. 
Increase in the number of cycle parking facilities in the city centre by $4000 \%$. Increase in the number of cyclists in the city centre by $47 \%$.

Decrease in the use of solo cars by Council employees by $5 \%$.

Conversion of $6 \%$ of Council light vehicles fleet to run on lower emission fuel. Increase citizen awareness of sustainable transport patterns.

Reduction of car traffic levels to $97 \%$ of predicted levels.

As part of the EU CIVITAS programme a cross-project evaluation was undertaken, METEOR. METEOR provided guidelines to the MIRACLES project on the evaluation framework at measure and city level and on reporting templates. However, in the authors' opinion this was an idealised framework and often found cumbersome when applied to projects.

University College Cork evaluated the measures in Cork as part of the MIRACLES Evaluation Group, led by University of Southampton's Transportation Research Group.

\section{Evaluation framework}

In-project evaluation assessment is an area in which little research has been conducted. Internationally it is being driven by the need to monitor and run projects in the best way possible. Monitoring project implementation identifies problem areas and the areas in which a project is working well, as well as monitoring the achievement of project goals and objectives.

Limitations exist with the traditional cost-benefit analysis required for road schemes; although an Environmental Impact Study may be required it is often not combined with the cost benefit analysis and many impacts may not be included. Additionally, unlike most road schemes, transport management schemes are typically implemented in urban settings with a higher impact on the day-to-day lives of citizens, which demands a higher degree of observation on the social impacts. The areas of environment (including energy), transport (including safety), economy and society (including integration and accessibility) need to be examined and evaluated.

Perceptions and acceptability of transport management schemes are often difficult to quantify. "It is useful to transfer this experience [from social science] to the field of traffic engineering in order to evaluate traffic management schemes more comprehensively, by considering people's perceptions and actions. In many fields of study, quantitative and qualitative approaches can be viewed as complementary and mutually supportive" [3].

The innovative nature of the Cork MIRACLES measures required a new evaluation framework so that all impacts could be monitored and feedback provided during the implementation process.

Based on the experience gained from the Cork evaluation of the MIRACLES measures, the authors developed a 14-step evaluation process, shown in fig. 1, which codifies some of the evaluation techniques used in MIRACLES together with the authors' views of evaluation best practice. 


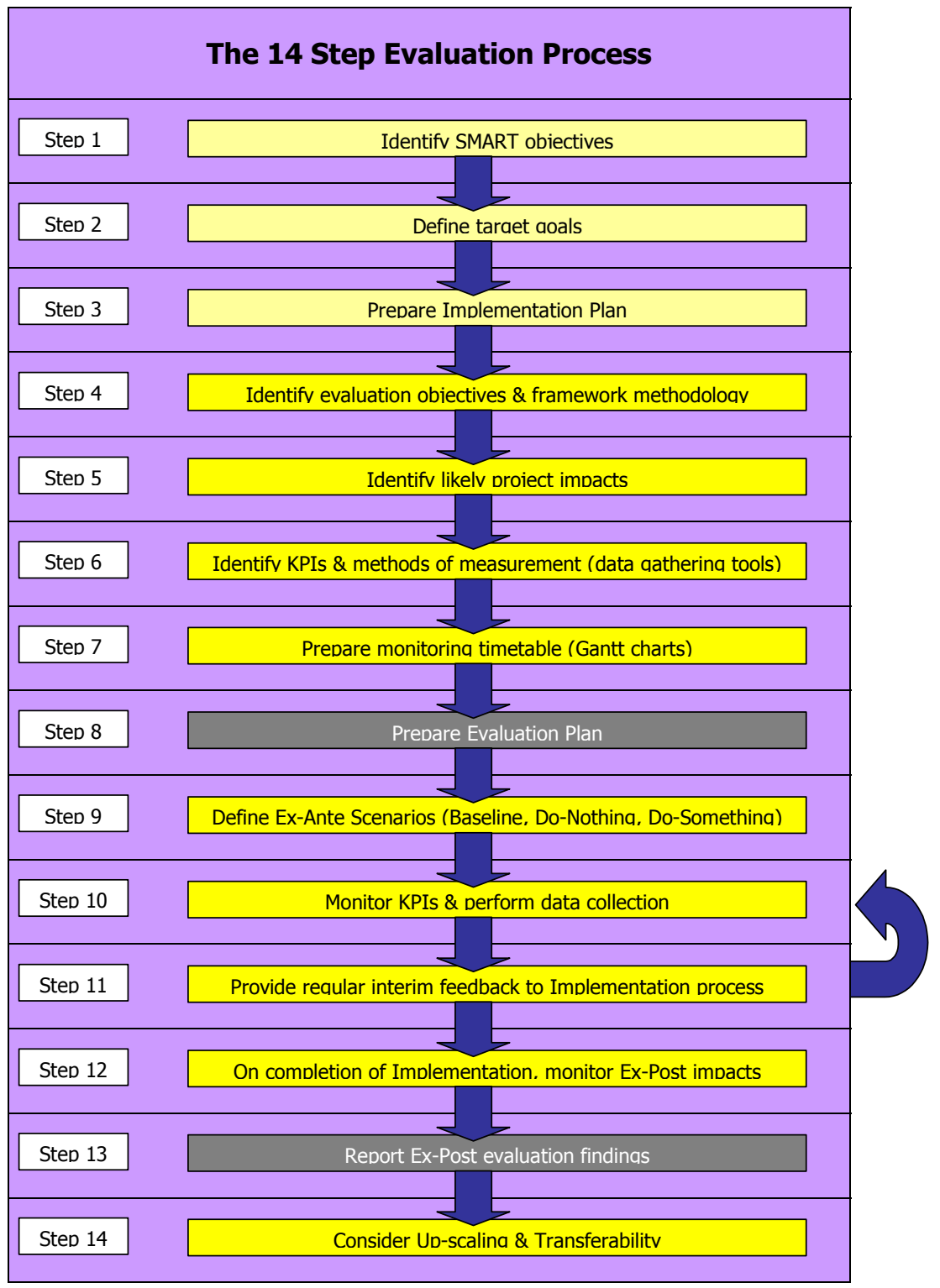

Figure 1: The 14-step evaluation process.

Project inception (Steps 1 to 3, in fig. 1) is the area in which most evaluation research has been conducted to date; its importance has been driven by the best allocation of funding among possible projects. Typically it is examined through cost-benefit analysis or multi-criteria analysis. Steps 1 to 3 set out measures, identify their goals and objectives, and plan the technical implementation. 
The next step is to identify evaluation objectives and the framework methodology (Step 4). A comprehensive evaluation framework rather than the traditional restricted capacity/benefit approach is needed in order to monitor the complexities of transport management measures. The comprehensive evaluation framework examines the generated impacts of the measures (Step 5).

Integrating qualitative and quantitative methods was considered to be the most appropriate method of evaluating transport management measures due to the social benefits and costs involved as well as the economic, environmental and transportation impacts. The approach to assessing the impacts during the Cork MIRACLES case study was a mixed method evaluation. This utilised a comprehensive multi-criteria evaluation framework with key performance indicators (KPIs), which are later discussed in Section 4 (Steps 6 and 7).

Evaluation design (Step 8), the Cork MIRACLES project first established the appropriate evaluation questions, information, needs, and sources of information based on the objectives of the measures. The analysis strategy was then developed; this identified and applied appropriate techniques and procedures for information collection, processing and analysis. The various measures were examined in detail and indicators were identified, and an evaluation matrix was drawn up. The evaluation matrix enabled the study of each indicator in relation to different measures and also aided in identifying possible common data collection. The MIRACLES evaluation plan [2] can be found on the MIRACLES website www.miraclesproject.org.

\subsection{Scenario development}

An important part of the case study evaluation process was the development of various scenarios. The baseline was first developed in order to record the situation pre-implementation of the project. The do-nothing was a frozen scenario, similar to the baseline, but for a future year with only traffic growth applied. The do-something is for the future year but including the expected impacts of the Cork MIRACLES measures and any parallel projects likely to be implemented over the lifespan of the project. The baseline, do-nothing and do-something scenarios all form the ex-ante evaluation.

The definition of the baseline and do-nothing scenarios (Step 9) were vital in terms of evaluation as it is from these that the measures were initially compared. While do-something scenarios are often useful in comparing what was predicted to happen to what actually did happen (the ex-post scenario), it was not considered essential by the Rome and Winchester evaluators in the MIRACLES project. The monitoring of the ex-post scenario considered to be of far higher importance. For Cork, the do-something scenario was compared with the ex-post in order to relate the predictions made with the actual outcomes. This proved useful in terms of setting targets for each of the KPIs. The choice of a baseline and ex-post year is vital in terms of monitoring the effects of the measures. It was necessary to choose the baseline year as one for which substantial information (e.g. census, national traffic counts, and national accident rates) was available, as this did not require trend estimations. 


\subsection{Evaluation type}

Formative evaluations are assessments of how well a project is being implemented, or how closely project implementation fits with the intentions of policy-makers. Formative evaluations provide the opportunity to give continuous feedback throughout the lifetime of a project, meaning that the project can be redirected. Summative evaluations assess whether the project achieved its desired objectives as defined by Allard [6]. The Cork MIRACLES case study was summatively evaluated through means of the ex-post surveys and the MIRACLES Cork Measure Templates [5]. The Formative evaluation also produced information that was fed back during the development of the project in order to improve the performance of the project, using survey findings.

The following evaluation types were carried out in the Cork MIRACLES case study:

- Diagnostic evaluation during the design and planning of the project.

- Monitoring evaluation once the project was under way (Step 10).

- Process evaluation improved the activities that were implemented (Step 11).

- Impact evaluation determined if the project had the desired effect (Step 12).

\subsection{Meta-evaluation}

Meta-evaluation is the evaluation of the evaluation process and its results, this ensures that the entire process is monitored and considered for validity and reliability, and can lend support towards the findings of the evaluation. Metaevaluation is a necessary step in the evaluation process and, while concerned with the outcomes and findings, should be an integral part of the whole process from beginning to end. The authors recommend that meta-evaluation should be conducted simultaneously and in parallel to the 14-step evaluation process.

Meta-evaluation ensured that the entire process of the evaluation of the MIRACLES project was monitored and considered for validity and reliability. In addition to the external meta-evaluation, internal meta-evaluation took place in the form of data quality assessments. While the University of Southampton performed the internal meta-evaluation, METEOR performed the external metaevaluation.

\section{Key performance indicators}

Key performance indicators provide a means of monitoring and analysing measures as they are implemented in order to determine how well they are performing, they also ascertain how they are performing with regard to the intended objectives (Step 6). KPIs are also referred to as measures of effectiveness. The advantage of using KPIs is that they can be modified as needed if the project has unpredicted outcomes or impacts, as well as continually monitoring the performance of a project (Step 11). 
KPIs vary in both number and extent depending on the scale of the measure. The significance of these indicators is also important as many indicators will not affect the overall transport strategy but will be significant to individual measures. Indicators should be Specific, Measurable, Attainable, Relevant and Timed.

Specific: The selection of KPIs can be an arduous and time-consuming task. All major impacts and performance aspects should be examined. The identification, suggestion, reviewing and agreement on a list of key indicators, while extremely important, can result in considerable time delays.

Measurable \& Attainable: The evaluation tools used for each of the indicators can be divided into general categories: questionnaires, observed measurements, estimation and modelling. The data source and certainty of gathering information for each KPI are set out in the Evaluation Plan.

Relevant: As the project is implemented KPIs are reviewed and where necessary supplemented to in order to monitor all impacts.

Timed: The timing and frequency of data collection for each KPI is outlined in the Evaluation Plan.

The international experience of the many involved parties in the MIRACLES project enabled a relevant and comprehensive list of indicators to be agreed upon, which ultimately improved the evaluation of all the individual partners.

Gantt charts were used throughout the duration of the MIRACLES project. These charts not only allowed for project monitoring, but aid in a flexible approach to the realities of project design. Gantt charts [7] are simple displays that include proportionate, chronologically scaled time frames for each evaluation task. Gantt charts are very useful in terms of project planning/management as well aiding in the collect of data/information to aid the evaluation process (Step 7).

Table 1 is an example of the indicators monitored for one of the Cork MIRACLES measures which provided a new park and ride facility. The KPIs as well as their method of measurement, data source, units and certainty of collection $(* * *$ to be carried out by evaluators, ** information needed from project manager, * information needed from external source) were set out in the Cork MIRACLES Evaluation Plan [2].

Data methodology sheets: as data was collected for each KPI before, during and after the project it is essential that the method, description, numbering, source and units of each indicator, were set out so the data is comparable. In the MIRACLES project, the data methodology sheets were set out by METEOR [4] and 28 core city indicators were identified.

MIRACLES measures were examined both at the micro (measure) and macro (city) level. METEOR core indicators were examined at city level, but the timing of information availability, suitability and quantity led to some difficulties in matching them to the different local contexts. "The METEOR indicators are not always appropriate: they are not sufficient to define particular measures to be implemented in some cities (for instance for the case of Rome, specific indicators for parking measures are missing), some other indicators seem to be excessive for the evaluation of the measures (as in the case of Cork)" [2]. 
No formal weighting of the indicators was used in the MIRACLES project in Cork or in any of the other cities. However, during the course of the data collection, analysis and monitoring process, an informal weighting occurred in Cork in terms of how often and how many man-hours were assigned to each of the indicators. Allowing indicators to combine and overlap can provide opportunities for cost cutting in terms of resource management (e.g. Park and Ride surveys - user acceptance, security rating, etc.)

Table 1: $\quad$ Modified from Measure Level Template WP7.3 Park and Ride [2].

\begin{tabular}{|c|c|c|c|c|c|}
\hline $\begin{array}{l}\text { Evaluation } \\
\text { Category }\end{array}$ & Impact & Indicator (Units) & Method & Data Sources & Certainty \\
\hline \multirow[t]{3}{*}{ Environment } & Emissions & Emissions $\left(\mathrm{ug} / \mathrm{m}^{3}\right)$ & Estimated & Change calc by veh type & $* * *$ \\
\hline & Change in derelict land & Change in derelict area (\%) & Measured & Design specifications (CCC) & $* *$ \\
\hline & Energy Efficiency & Change in total fuel use (GJ) & Measured & Consumption values & $* * *$ \\
\hline \multirow[t]{3}{*}{ Safety } & Transport safety & Accidents (No of acc/year) & Measured & Accident database (NRA) & $*$ \\
\hline & \multirow[t]{2}{*}{ Security (on site) } & Safety rating (Index) & Questionnaire & Questionnaire results & $* * *$ \\
\hline & & Incident levels (Number/year) & Measured & $\begin{array}{l}\text { Recorded on-site \& bus } \\
\text { (CCC) }\end{array}$ & $* *$ \\
\hline \multirow{2}{*}{$\begin{array}{l}\text { User } \\
\text { Acceptance }\end{array}$} & Operator acceptance & Acceptance rating (Index) & Questionnaire & Questionnaire & $* * *$ \\
\hline & User acceptance & Acceptance rating (Index) & Questionnaire & Questionnaire & $* * *$ \\
\hline \multirow{11}{*}{$\begin{array}{l}\text { Transport } \\
\text { System }\end{array}$} & Congestion & Journey times (Minutes) & Observed & Surveys & $* * *$ \\
\hline & \multirow[t]{3}{*}{ Network capacity } & Passenger capacity (pkm/day) & Measured & Bus capacity (Bus Eireann) & $* *$ \\
\hline & & Parking spaces (Number) & Observed & No. on site / No. occupied & $* * *$ \\
\hline & & Patronage (pax/day) & Measured & Ticket receipts (Bus Eireann) & $* *$ \\
\hline & Network efficiency & Passenger load factors (\%) & Measured & $\%$ bus spaces used & $* * *$ \\
\hline & Modal split & Average modal split ( $\%$ by mode) & Measured & Questionnaire & $* * *$ \\
\hline & \multirow[t]{2}{*}{$\begin{array}{l}\text { Availability of } \\
\text { information }\end{array}$} & Information sites (Number) & Measured & No. of sites provided(CCC) & $* *$ \\
\hline & & Information accessibility (Index) & Questionnaire & Questionnaire & $* * *$ \\
\hline & Frequency & Average headway (Minutes) & Observed & Average times between buses & $* * *$ \\
\hline & \multirow[t]{2}{*}{ Reliability } & $\begin{array}{l}\text { Variability of arrival times } \\
\text { (Minutes) }\end{array}$ & Observed & Actual \& scheduled times & $* * *$ \\
\hline & & $\begin{array}{l}\text { Variability of journey } \\
\text { times(Minutes) }\end{array}$ & Observed & Actual \& scheduled times & $* * *$ \\
\hline \multirow[t]{7}{*}{ Economic } & Infrastructure cost & Purchase cost $(€)$ & Cost statement & Financial records (CCC) & $* *$ \\
\hline & \multirow[t]{2}{*}{ Operating cost } & Power cost ( $€ /$ year $)$ & Cost statement & Financial records (CCC) & $* *$ \\
\hline & & Contract cost $(€)$ & Cost statement & Financial records (CCC) & $* *$ \\
\hline & Maintenance cost & Maintenance cost ( $€ /$ space $)$ & Cost statement & Financial records (CCC) & $* *$ \\
\hline & Subsidy & Subsidy [bus] ( $€ / \mathrm{km} /$ year) & Cost statement & Financial records (CCC) & $* *$ \\
\hline & $\begin{array}{l}\text { Temporary jobs } \\
\text { provided }\end{array}$ & Number employed (Number) & Measured & Financial records (CCC) & $* *$ \\
\hline & $\begin{array}{l}\text { Long term jobs } \\
\text { provided }\end{array}$ & Number employed (Number) & Measured & Financial records (CCC) & $* *$ \\
\hline
\end{tabular}

Formal weighting may be useful but are not suitable for projects which are innovative and may have unforeseen effects, have delayed implementation, or unknown goals. Indicators can be weighted by importance as is done in multicriteria analysis. However, importance is a subjective decision which can vary depending on the stakeholder. Transport management projects often have 
multiple and varied stakeholders, each with their own opinions on the importance and ranking of the KPIs. The ranking of indicators into a unanimously accepted order can cause significant time delays and expend much of the resources set aside for evaluation.

\section{Discussion}

Measures in Cork were relatively modest, and the approach set by METEOR, in terms of both methodology and indicators, seemed excessive. The significance of changes brought about by MIRACLES compared with external projects (e.g. Green Routes project, City of Culture 2005) was uncertain. There were only minimal changes in the city level indicators. At microscopic (measure) level, significant changes were predicted and quantified in the before and after evaluations.

The comprehensive framework in this paper was able to accommodate change throughout a project. The scale of the project is the critical factor in deciding on the detail of evaluation that should be carried out. Only large-scale projects can warrant the investment in detailed optimisation modelling due to the financial, manpower and time requirements.

Ex-post evaluation should provide a comprehensive and detailed review of the elements of success and failure of the project. Up-scaling and transferability were also considered for the case study. Transferability was considered to transfer a measure within a city or to another city/country (Step 14). Once a measure (or a package of measures) has proved successful in a city, the same measure may prove to be successful elsewhere. The replication of a project in a different context is however subject to certain conditions of transferability [8].

Post-project assessment is an area in which further study is required, including the impacts of projects over time and the unforeseen consequences after the completion of a project. The assessment period should be examined, as well as whether the project has been a catalyst for other things (other projects, expansions, up-scaling or transferability).

\section{Acknowledgements}

The authors would like to thank Cork City Council and the MIRACLES project Evaluation Group.

\section{References}

[1] Oxera Consulting Ltd. How should the ex post evaluation of trunk road schemes be enhanced? Report prepared for the UK Department for Transport. 2005. www.oxera.co.uk.

[2] MIRACLES. Evaluation Plan Deliverable D4.1 - February 2003. www.miraclesproject.org 
[3] Goodwin, W. \& Goodwin, L. Understanding quantitative and qualitative research in early childhood education. Teachers College Press. NY. 1996.

[4] METEOR. D2 Assessment Framework and Evaluation Guidelines for Data Collection. METEOR - Monitoring and Evaluation of Transport and Energy Oriented Radical Strategies for Clean Urban Transport. 2003

[5] MIRACLES. Final Evaluation Report Deliverable D4.2 - March 2006. www.miraclesproject.org

[6] Allard, S.W. Quantitative Analysis - Program Evaluation (PPA 722). Department of Public Administration Maxwell School of Citizenship and Public Affairs Syracuse University, NY. 2004. http://classes.maxwell.syr.edu/ppa722/

[7] Clark, N. The Gantt Chart. London Pitman and Sons. 1952.

[8] Macário, R., \& Marques, C. Transferability of Transport Policies and Measures in CIVITAS. METEOR - Monitoring and Evaluation of Transport and Energy Oriented Radical Strategies for Clean Urban Transport. 2004. 